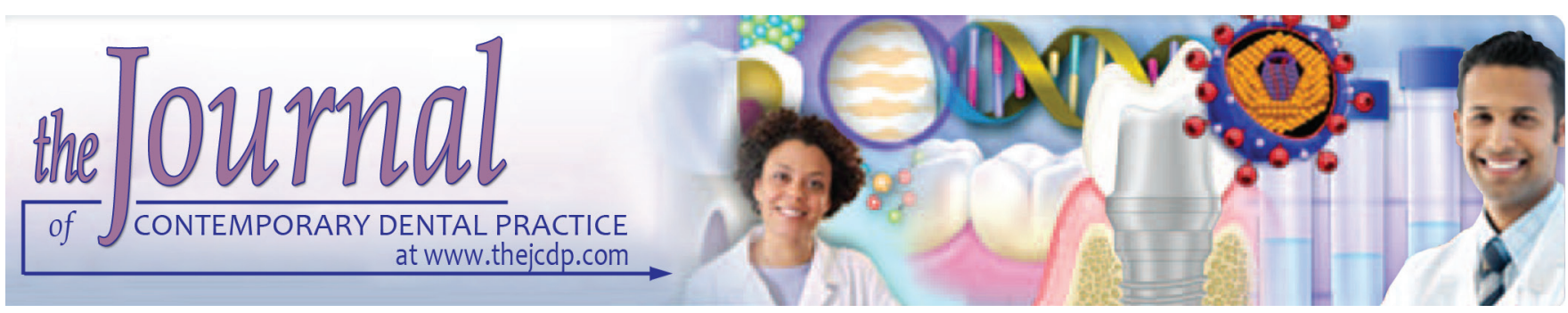

\title{
Effect of Casein Phosphopeptide-Amorphous Calcium Phosphate and Three Calcium Phosphate on Enamel Microhardness
}

${ }^{1}$ En HR Haghgou, ${ }^{2}$ Roza Haghgoo, ${ }^{3}$ Mohamad R Roholahi, ${ }^{4}$ Zahra Ghorbani

\begin{abstract}
Aim: This study aims to investigate the effect of casein phosphopeptide-amorphous calcium phosphate and three calcium phosphate (CPP-ACP and TCP) on increasing the microhardness of human enamel after induction of erosion.

Materials and methods: A total of 26 healthy human-impacted third molar teeth were chosen, and their hardness measured using a microhardness testing machine. The samples were immersed in Coca Cola $(\mathrm{pH}=4.7)$ for 8 minutes. Then, microhardness was measured again, and these samples were randomly divided into four groups (two control groups and two experimental groups). (1) Negative control group: Artificial saliva was used for 10 minutes, (2) positive control group: Fluoride gel was used for 10 minutes, (3) $\beta$-TCP group: TCP was used for 10 minutes, (4) CCP-ACP group: CCP-ACP was used for 10 minutes. The final microhardness of those samples was measured, and the changes in microhardness of teeth within group and between groups were analyzed using the paired and analysis of variance tests respectively. Results were considered statistically significant at a level of $p<0.05$.
\end{abstract}

Results: No significant difference was observed in microhardness between CPP-ACP group and TCP group $(p=0.368)$ during the time microhardness significantly dropped after soaking in soda.

Conclusion: Casein phosphopeptide-amorphous calcium phosphate and TCP increased the microhardness of teeth.

\footnotetext{
${ }^{1}$ Department of Materials and Energy, Research Center of Material and Energy, Tehran, Islamic Republic of Iran

${ }^{2}$ Department of Pediatric Dentistry, Dental School, Shahed University, Tehran, Islamic Republic of Iran

${ }^{3}$ Department of Restorative Dentistry, Dental School, Shahed University, Tehran, Islamic Republic of Iran

${ }^{4}$ Dentist, Private office, Tehran, Islamic Republic of Iran

Corresponding Author: Roza Haghgoo, N71, Italia Street Vesal Ave, Tehran, Iran, Phone: +982188956227, e-mail: haghgoodent@yahoo.com
}

The increase in hardness in the TCP group was higher than in the CPP-ACP group, but this difference was not significant $(p=0.36)$.

Clinical significance: Casein phosphopeptide-amorphous calcium phosphate and TCP can affect the remineralization of erosive lesions.

Keywords: Casein phosphopeptide-amorphous calcium phosphate, Demineralization, Dental enamel, Erosion, Microhardness, Remineralization, Three calcium phosphate.

How to cite this article: Haghgou EHR, Haghgoo R, Roholahi MR, Ghorbani Z. Effect of Casein Phosphopeptide-Amorphous Calcium Phosphate and Three Calcium Phosphate on Enamel Microhardness. J Contemp Dent Pract 2017;18(7):583-586.

Source of Support: Nil

Conflict of Interest: None

\section{INTRODUCTION}

Erosion is irreversible destruction of tooth structure by chemical process without the activity of bacteria on the teeth. ${ }^{1,2}$ Clinical problems and complications of erosion include the loss of the glossy surface of teeth and the smooth convex surface of teeth. ${ }^{2}$

Fluoride is one of the most effective remineralization agents in the treatment of demineralized lesions. ${ }^{3}$ However, chronic exposure to low levels of fluoride can cause problems in normal body systems (digestion, genitourinary, and respiratory). ${ }^{4}$ On the contrary, the prevalence of dental fluorosis has increased, especially in nonfluoridated areas. ${ }^{4-6}$ Furthermore, fluoride ion alone cannot completely remineralize dental demineralized lesions. ${ }^{7,8}$ In addition to fluoride, calcium and phosphate ions are needed to form per unit of fluorapatite. ${ }^{2}$ Therefore, it seems necessary to replace fluoride with materials that can remineralize the demineralized lesions. 
In the last decade, there has been a tendency to use different combinations containing calcium and phosphate, which can affect dental remineralization. Different groups of foods contain these mineral compounds, some of which include $\beta$-three calcium phosphate (TCP) and casein phosphopeptide-amorphous calcium phosphate (CPP-ACP) ${ }^{9,10}$

The results of studies on the chemical composition and materials that contain calcium and phosphate, such as CPP-ACP and $\beta$-TCP, show the mineralizing action of these materials on the surface of teeth. ${ }^{11,12}$

In the most recent studies, these materials have not been comprehensively investigated; in many, the materials were used with toothpaste, chewing gum, or mouthwashes that contain fluoride. Furthermore, the remineralizing effect of these two materials was not compared.

The purpose of this study was to investigate and compare the effect of CPP-ACP and TCP on increasing the microhardness of human enamel after erosion.

\section{MATERIALS AND METHODS}

In this research, 26 impacted third molar teeth were used. They did not have cavities, hyperplasia, enamel crack, and erosion. The teeth were placed in glass containers containing water of Tehran, after extraction by surgery. The water of these glasses was changed every 2 days to prevent changes in the surface of water and water pollution. The samples were mounted in a special frame with clear polyester after brushing teeth and cleaning up any debris. The samples were polished in the presence of water with polishers and a polish device to achieve a flat and suitable surface for measuring microhardness. Then, the surface of samples was dried, and the initial microhardness was measured using the Vickers method.
Consistent with previous articles, $50 \mathrm{~g}$ of force was chosen for this research. ${ }^{13}$

The samples were immersed in delestre for 8 minutes. The beverage was changed every 2 minutes to make sure that the buffering effect of dissolved ions from the enamel surface was not reduced and that the beverage gas remained. ${ }^{14}$ Then, the microhardness was measured for the second time. Thereafter, teeth were randomly divided into two groups of 10 and two groups of 3 . Groups of 10 were placed into $\beta$-TCP and CPP-ACP (tooth mousse) and groups of three (positive and negative control group) were placed into fluoride gel and artificial saliva respectively, for 10 minutes.

Then, the microhardness of teeth was measured for the third time. The data were analyzed using Statistical Package for the Social Sciences version 22 software. Descriptive features, including mean and standard deviation, and inferential statistics, including analysis of variance, were performed. Comparisons between groups were made using the Duncan multiple range test, and paired sample t-test was used to compare groups before and after the experiment.

\section{RESULTS}

No significant difference was observed between two treatments groups in microhardness $(p=0.368)$. During the time, microhardness significantly dropped after soaking in soda $(p=0.000)$ (Table 1$)$. Microhardness was significantly increased in both groups after the treatment $(p=0.000)($ Table 2$)$.

\section{DISCUSSION}

Erosion is the destruction of tooth structure without interference or the activity of microorganisms. Erosion plays an important role in the destruction of dental tissues. ${ }^{15}$

Table 1: Primary and secondary microhardness (before and after soaking in soda) statistical indicator

\begin{tabular}{llllll}
\hline & Sample size & $\begin{array}{l}\text { Time of effect } \\
\text { (in minute) }\end{array}$ & $\begin{array}{l}\text { Mean of primary } \\
\text { microhardness }\end{array}$ & $\begin{array}{l}\text { Mean of secondary } \\
\text { microhardness }\end{array}$ & $p$-value \\
\hline Group & & & & & \\
S & 3 & 8 & 450 & 261 & 0.000 \\
F & 3 & 8 & 359 & 268 & \\
TM & 10 & 8 & 490 & 259 & \\
TCP & 10 & 8 & 472 & & \\
\hline
\end{tabular}

S: Saliva, F: Fluoride, TM: CPP-ACP (tooth mousse)

Table 2: Primary microhardness, after demineralization and after intervention

\begin{tabular}{|c|c|c|c|c|c|c|c|}
\hline Experimental groups & Number & \multicolumn{2}{|c|}{ Primary evaluation } & \multicolumn{2}{|c|}{ After demineralization } & \multicolumn{2}{|c|}{ After intervention } \\
\hline$S$ & 3 & $88 / 459$ & 450 & $13 / 892$ & 261 & 38 & 326 \\
\hline $\mathrm{F}$ & 3 & $55 / 561$ & 359 & $16 / 462$ & 268 & $54 / 781$ & 358 \\
\hline TM & 10 & $56 / 272$ & $490 / 10$ & $54 / 319$ & $275 / 10$ & $41 / 884$ & $378 / 60$ \\
\hline TCP & 10 & $53 / 442$ & $472 / 70$ & $28 / 386$ & 259 & $30 / 840$ & 366 \\
\hline Total & 26 & $68 / 485$ & $463 / 65$ & $39 / 229$ & $269 / 69$ & $39 / 903$ & $365 / 31$ \\
\hline & & $88 / 459$ & 450 & $13 / 892$ & 261 & 38 & 326 \\
\hline
\end{tabular}

S: Saliva, F: Fluoride, TM: CPP-ACP (tooth mousse) 
Therefore, application of repairing material of erosive lesions is necessary.

In this research, the effect of $\beta$-TCP and CPP-ACP on remineralization of erosive lesions created by exposure to delestre was investigated.

According to the results, the microhardness of tooth enamel decreased significantly by $41 \%$ after exposure to carbonated beverage.

The results of Ghajari and Razavi's ${ }^{16}$ research, which investigated the effect of Iranian and foreign beverage $\mathrm{pH}$ on the amount of dental erosion by analysis of calcium method, showed that calcium was taken from the surface of tooth enamel after exposure to the beverage, consistent with our findings.

The results of the study by Haghgoo et al, ${ }^{17}$ which investigated the effect of nano-hydroxyapatite solution on mineralization of permanent teeth exposed to delestre, showed that delestre significantly decreases the microhardness of tooth enamel, consistent with our research.

According to the results of this research, the increase of microhardness in the artificial saliva group was $24 \%$. Saliva is capable of keeping the mouth environment oversaturated with calcium and phosphate ions. This leads to the protection of hydroxyapatite crystals and increases the power of repairing the tooth enamel structure. ${ }^{18}$ However, oral conditions can proceed to demineralization because of various causes and, in some conditions, the use of remineralization agents is necessary to promote conditions that favor of remineralization. ${ }^{19}$

According to the results of this research, microhardness of tooth enamel increased by $37 \%$ after exposure to ACP-CPP. This increase could be due to the presence of amorphous and settle ability of calcium and phosphorus ions in this material. On the contrary, saturation with calcium and phosphorus ions changes acidity into alkalinity. ${ }^{20}$ Furthermore, ACP-CCP can act as a calcium reservoir along with remineralization. This material is designed so as to stabilize calcium and phosphorus ions on the surface of the tooth. ${ }^{21-24}$

The results of this research showed that microhardness of tooth enamel increased by $41 \%$ after exposure to $\beta$-TCP. The base of $\beta$-TCP is calcium and phosphate, and its chemical formula is $\mathrm{Ca}_{3}\left(\mathrm{PO}_{4}\right)_{2} \cdot{ }^{9}$ This calcium and phosphate base confers on this material the ability to increase microhardness.

The results reported by Robert and Rezvani indicate that the impact of $\beta$-TCP and ACP-CPP on improving lesions ${ }^{9,11}$ is consistent with the results of our research.

In the present research, 10 minutes was allocated for exposure to remineralization agents, because longer times are difficult for patients and would create an experimental scenario that diverges from clinical criteria. In previous research, the time of exposure to remineralization materials was too long to be clinically difficult. ${ }^{16,25}$

In this research, we investigate the impact of two materials $\beta$-TCP and ACP-CPP on the microhardness of tooth enamel after erosion in vitro.

It is suggested that this research is done in situ because of the simulation of the mouth and considering the impact of diet.

\section{CONCLUSION}

According to the results of the present study, TCP and CPP-ACP can affect remineralization of erosive lesions.

\section{CLINICAL SIGNIFICANCE}

Three calcium phosphate and CPP-ACP can affect the remineralization of erosive lesions.

\section{REFERENCES}

1. Petersson GH, Bratthall D. The caries decline: a review of reviews. Eur J Oral Sci 1996 Aug;104(4):436-443.

2. Kitchens M, Owens BM. Effect of carbonated beverages, coffee, sports and high energy drinks, and bottled water on the in vitro erosion characteristics of dental enamel. J Clin Pediatr Dent 2007 Spring;31(3):153-159.

3. Lenzi TL, Montagner AF, Soares FZ, de Oliveira Rocha R. Are topical fluorides effective for treating incipient carious lesions? A systematic review and meta-analysis. J Am Dent Assoc 2016 Feb;147(2):84.e1-91.e1.

4. Jha SK, Mishra VK, Sharma DK, Damodaran T. Fluoride in the environment and its metabolism in humans. Rev Environ Contam Toxicol 2011 Jan;211:121-142.

5. Pendrys DG. Dental fluorosis in perspective. J Am Dent Assoc 1991 Sep;122(9):63-66

6. Newbrun E. Current regulations and recommendations concerning water fluoridation, fluoride supplements, and topical fluoride agents. J Dent Res 1992 May;71(5):1255-1265.

7. Selwitz RH, Ismail AI, Pitts NB. Dental caries. Lancet 2007 Jan;369(9555):51-59.

8. Fejerskov, O.; Cury, JA.; Tenuta, LM.; Marinho, VC. Fluorides in caries control? In: Fejerskov O, Kidd E, editors. Dental caries: the disease and its clinical management. 3rd ed. Oxford: Blackwell Munksgaard; 2015. p. 217-220a, 123-141b, 214c, 288-320d.

9. Karlinsey RL, Mackey AC, Walke ER, Frederick KE. Surfactant-modified TCP: structure, properties, and in vitro remineralization of subsurface enamel lesions. J Mater Sci Mater Med 2010 Jul;21(7):2009-2020.

10. Heshmat H, Banava S, Mohammadi E, Kharazifard MJ, Mojtahedzadeh F. The effect of recommending a CPP-ACPF product on salivary and plaque $\mathrm{pH}$ levels in orthodontic patients: a randomized cross-over clinical trial. Acta Odontol Scand 2014 Nov;72(8):903-907.

11. Rezvani MB, Karimi M, Rasoolzade RA, Haghgoo R. Comparing the effects of whey extract and casein phosphopeptide-amorphous calcium phosphate (CPP-ACP) on enamel microhardness. J Dent (Shiraz) 2015 Mar;16(1):49-53. 
12. Tavassoli-Hojjati S, Atai M, Haghgoo R, Rahimian-Imam S, Kameli S, Ahmaian-Babaki F, Ahmadyar M. Comparison of various concentrations of tricalcium phosphate nanoparticles on mechanical properties and remineralization of fissure sealants. J Dent (Tehran) 2014 Jul;11(4):379-388.

13. Haghgoo R, Abbasi F, Rezvani MB. Evaluation of the effect of nano hydroxyl apatite on erosive lesions of the enamels of permanent teeth following exposure to soft beer in vitro. Sci Res Essays 2011 Nov;6(28):5933-5936.

14. Haghgoo R, Tabar FF. The effect of carbonate beverage and soft bear on enamel micro hardness of permanent teeth. J Dent Shiraz Univ Med Sci 2010 Jun;11(2):154-160.

15. Kitchens M, Owens BM. Effect of carbonated beverages, coffee, sports and high energy drinks, and bottled water on the in vitro erosion characteristics of dental enamel. J Clin Pediatr Dent 2007 Spring;31(3):153-159.

16. Ghajari MF, Razavi SN. Comparing the effect of Iranian soft drinks with the standard sample; calcium ion analysis. J Dent Med 2007 Apr;20(1):27-32.

17. Haghgoo R, Reza HH, Farid A, Mohammad T. The effect of nano-hydroxy apatite solution on the permanent tooth remineralization following exposure to soft beer (in situ). J Dent Med 2014 Dec;27(4):233-240.

18. Cochrane NJ, Cai F, Huq NL, Burrow MF, Reynolds EC. New approaches to enhanced remineralization of tooth enamel. J Dent Res 2010 Nov;89(11):1187-1197.
19. Hay DI. Salivary factors in caries models. Adv Dent Res 1995 Nov;9(3):239-243.

20. Andersson A, Skold-Larsson K, Hallgren A, Petersson LG, Twetman S. Effect of a dental cream containing amorphous cream phosphate complexes on white spot lesion regression assessed by laserfluorescence. Oral Health Prev Dent 2007;5(3):229-233.

21. Caruana PC, Mulaify SA, Moazzez R, Bartlett D. The effect of casein and calcium containing paste on plaque $\mathrm{pH}$ following a subsequent carbohydrate challenge. J Dent 2009 Jul;37(7):522-526.

22. Kitasako Y, Cochrane NJ, Khairul M, Shida K, Adams GG, Burrow MF, Reynolds EC, Tagami J. The clinical application of surface $\mathrm{pH}$ measurements to longitudinally assess white spot enamel lesions. J Dent 2010 Jul;38(7):584-590.

23. Borges BC, de souza Borges J, de Araujo LS, Machado CT, Dos Santos AJ, de Assuncao Pinheiro IV. Update on nonsurgical; ultraconservative approaches to treat effectively noncavitated caries lesion in permanent teeth. Eur J Dent 2011 Apr;5(2):220-236.

24. Kim M, Kwon HK, Choi CH, Kim BI. Combined effects of nano-hydroxyapatite and $\mathrm{NaF}$ on remineralization of early caries lesion. Key Eng Mater 2007 Feb;330-332:1347-1350.

25. Meng XC, Li XY, Lu KL. Study of nano-hydroxyapatite on the remineralization of dismineralized teeth. Mater Sci Forum 2005 Jan;475-479:2423-2426. 